\title{
Non-canonical Very as a Degree Modifier of NPs in English
}

\author{
Marcus V. R. Vieira ${ }^{1}$, Luciana Sanchez-Mendes ${ }^{1}$ \\ ${ }^{1}$ Universidade Federal Fluminense, Brasil \\ Correspondence: Luciana Sanchez-Mendes, Instituto de Letras UFF, Campus do Gragoatá, GEPEX, Marcos \\ Waldemar de Freitas Reis, Room 330, Building C, Niterói, Rio de Janeiro, Brasil.
}

Received: June 4, 2020

Accepted: June 30, 2020

Online Published: July 2, 2020

doi:10.5430/elr.v9n3p1

URL: https://doi.org/10.5430/elr.v9n3p1

\begin{abstract}
The aim of this paper is to investigate the meaning of constructions with a non-canonical use of very inside NPs and to propose a unified formal semantic analysis for the degree modifier very. We adopt the notion of scalar properties and take as a starting point the fact that very is a typical degree modifier that boosts the degree of open-scale adjectives (e.g. tall) (cf. Kennedy \& McNally, 2005). In this work, we focus on what we name non-canonical very: the modification of very on NPs (e.g. the very house John lived in). Our methodology consists of three major steps: firstly, we selected sentences with non-canonical very from The British National Corpus. Then, we selected sentences from five American and British novels published in the 19th and 20th centuries, comparing the sentences with their translations into Portuguese. Based on a first analysis of these sentences and on Matthewson's (2004) methodology, we proceed to controlled elicitation of contexts with the participation of a native-English speaker of Wales. Data collected present definite DPs and complex NPs, what supports a proposal that consider modification of a scale that is closed and contextually dependent. We argue in favor of an analysis that gives a uniform lexical entry to very and assume that the difference on interpretation of canonical and non-canonical modification is due to scalar properties of the modified predicate. Canonical very modifies lexical open scales whereas non-canonical very modifies contextual closed scales of precision and produces an exhaustive interpretation. The study reveals the importance of logical scalar properties for the semantic investigation of degree modifiers.
\end{abstract}

Keywords: very, degrees, modifiers, English, formal semantics

\section{Introduction}

This paper aims to investigate the meaning of constructions with a non-canonical use of very inside NPs.

From a descriptive view, according to the literature, very is an intensifier that modifies adjectives and adverbs. Crystal (2008: 248), for instance, defines intensifiers as 'a class of adverbs which have a heightening or lowering effect on the meaning of another element in the sentence'. In (1), there is an example of very intensifying an adjective:

John is very tall.

In (1), the property related to this adjective is higher than what is considered to be the standard stature in relation to a comparison class in the context.

The meaning of very interpreted as an intensifier can also be observed in the modification of adverbs of manner as well, such as in (2):

Roger drives very slowly.

In (2), very intensifies the adverb of manner slowly in a way that (2) can be interpreted as Roger drives much slower than what is considered to be the standard speed in the context.

Differently from its use as an intensifier, this paper focuses on a non-canonical use of very in sentences such as (3):

This is the very house where I lived in.

In (3), the sentence expresses that this is the exact house where I lived in. There is no heightening in any property.

The aim of this paper is to give a proper semantic analysis to very that captures both its intensifier operation and its non-canonical use. To do so, we adopt a scalar semantics following the framework of Kennedy \& McNally (2005). 
Following the descriptive generalizations, the modification performed by very is considered to be restricted to two domains (adjectives and adverbs), as seen in McNally \& Kennedy (2008: 8): "The case of the degree modifier very is interesting because its distribution is one of the classic diagnostics for distinguishing adjectives and adverbs from nouns and verbs: the former accept modification by very; (...) the latter never do."

Assuming a scalar semantics on the K\&M's framework, Doetjes (2008) agrees that the use of very is also restricted to certain scales that are typically adjectival, indicating that very cannot modify other domains.

Despite some description of this occurrence (e.g. Beltrama \& Bochnak, 2015; Bylinina \& Sudo, 2015), this paper focus on a gap in the literature on scalar semantics: the use of very with NPs. Therefore, the importance of this study is in its attempt to expand the use of scalar semantics to degree modification of NPs proposing a unified analysis for very in both uses, canonical and non-canonical. Furthermore, this study fits into a contemporary discussion involving the nature of degree modifications in the interface between Semantics and Pragmatics (e.g. McNally, 2016; Sawada, 2018).

This paper is divided as follows: section 2 presents the data selection that shows how we gathered the sentences in our study; section 3 presents the bases of scalar semantics that will be the tool for our analysis of non-canonical very presented in section 4; section 5 concludes addressing the open questions of the study.

\section{Data Selection}

Since authors of this paper are not native speakers of English, which means we are not provided with some introspective knowledge of this language to intuitively indicate whether a sentence with non-canonical very is grammatically acceptable or not, we proceed a selection of data aiming to demonstrate that this phenomenon exists and is quite frequent. Our data selection consists of three stages: the first one makes use of The British National Corpus $^{1}$, the second one makes use of some novels written in English and the third one is the controlled elicitation of contexts with the participation of a native English speaker as a consultant.

In relation to The British National Corpus, the first search entry of the occurrences of very results in more than one hundred thousand cases of sentences that illustrate modifications with very. Based on the fact that this number of sentences is somehow difficult to be approached, in order to lessen this number, the first 1000 sentences were selected to compose the data of this work.

At this level, the sentences were separated in two groups: the first group with the canonical modification of very (on adjectives and adverbs of manner) and the second one with the non-canonical modification (on NPs). Out of the 1000 sentences, the quantitative analysis shows that 72 are examples of the non-canonical modification, corresponding to $7,2 \%$ in total. Therefore, these numbers indicate that the occurrence of the canonical modification $(92,8 \%)$ is much higher when compared to the non-canonical modification. In (4) and (5), there are two cases of very modifying NPs from the BNC:

"The flexibility of the engine and the very nature in which the power is delivered mean far fewer gear changes are required..." (Good Adverts, 1985-1994)

"But this is the first time they have been attacked by the very people supposed to be enthusiastic about them." (The Daily Mirror, 1992)

In (4), very modifies the NP nature in which the power is delivered. In (5), very modifies the NP people supposed to be enthusiastic about them. In both sentences, it seems that very is interpreted as something like proper. Thus, the data from The British National Corpus confirm the existence of this type of modification in English.

The second stage consisted of verifying that the non-canonical modification of very is a consolidated phenomenon. To do this, the selection of five novels written in English in England and The USA in the $19^{\text {th }}$ and $20^{\text {th }}$ centuries became part of this work. In this stage we used the translations to Portuguese (native language of the authors) to gather some hints on the meaning conveyed by non-canonical very. The choice for novels of this period of time as a means of data selection can be justified by Baugh \& Cable's (2002) work, in the sense that the use of vocabulary and structures in written genres characterized a type of linguistic consolidation in Modern English in the $19^{\text {th }}$ century. We assumed that if we could find non-canonical very in novels of that period of time, we could assume that its use is consolidated.

\footnotetext{
${ }^{1}$ Created by Oxford University Press, The British National Corpus (BNC) is an online platform that contains linguistic data of English. Kennedy e McNally (2005), for instance, made use of this platform in order to verify the occurrences of very, much e well modifying participle adjectives.
} 
It is worth mentioning that we do not consider that the fact that the authors are not native English speakers as a problem. Contrariwise we think that our reflection on the translations' strategies adopted in the novels could give us a perspective of uses that can maybe be difficult for an English speaker untrained in Linguistics that knows how to employ the non-canonical very but not necessarily how to explain their uses.

Similarly to the methodology adopted with The British National Corpus, the sentences from the novels were categorized according to the nature of the adoption of very in canonical and non-canonical.

The first novel to be analyzed was Pride and Prejudice originally published in 1813, by Jane Austen ${ }^{2}$. We found 45 sentences with the non-canonical use of very in this novel. Following this direction, Northanger Abbey, first published in 1817 and Mansfield Park, published in 1814 (both Jane Austen's novels) were analyzed as well. In Northanger Abbey, 27 sentences of very modifying NPs were found whereas this number was 46 in Mansfield Park.

In order to expand our analysis in the sense of not being limited to Jane Austen's novels, we selected two other novels: Mrs. Dalloway, by Virginia Woolf, published in 1925, and The Great Gatsby, by Fitzgerald, also published in 1925. In Mrs. Dalloway, we found 19 sentences that represent the non-canonical use of very whereas 6 is the number of sentences found in The Great Gatsby. The table 1 below portrays the data from the novels quantitatively:

Table 1. Absolute value of the occurrences of very in the novels

\begin{tabular}{lccc}
\hline \multicolumn{1}{c}{ Novels } & $\begin{array}{c}\text { Canonical } \\
\text { modification }\end{array}$ & $\begin{array}{c}\text { Non-canonical } \\
\text { modification }\end{array}$ & Total \\
\hline Mansfield Park & 742 & 46 & 788 \\
Mrs. Dalloway & 131 & 19 & 150 \\
Northanger Abbey & 208 & 27 & 235 \\
Pride and Prejudice & 416 & 45 & 461 \\
The Great Gatsby & 51 & 6 & 57 \\
$\quad$ Total & 1548 & 143 & 1691
\end{tabular}

Table 1 shows 1691 sentences with very. Out of this total, 1548 are examples of canonical modification whereas 143 are examples of the non-canonical one. In terms of percentage, $92 \%$ represent the canonical use and $8 \%$ the non-canonical one. Similarly to the data from The British National Corpus $(92,8 \%$ vs $7,2 \%)$, the data from the novels also show that the canonical modification of very is much higher compared to the non-canonical one. Although there are less occurrences of non-canonical very, the data indicate the existence of it and its consolidation in English, based on both temporal existence and written consolidation.

The sentences (6), (7) and (8) are examples found in Jane Austen's novels. In (6), very modifies room and, in (7), the modification is on circumstance which had driven Julia away. In (8), very modifies first day that Morland came to us last Christmas and the first moment I beheld him. In (6) and (7), very is translated to mesma 'same' in the editions consulted of Pride and Prejudice translated to Orgulho e Preconceito (1996) in Portuguese and it is also translated to mesma 'same' in Mansfield Park (2011). In (8), it was simply omitted from the translation of Northanger Abbey (2012).

"He made her an offer in this very room, and she refused him." (Pride and Prejudice, 2005: 92)

"Ele propôs-se-lhe nesta mesma sala e ela recusou-o." (Orgulho e Preconceito, 1996: 190)

"...for the very circumstance which had driven Julia away was to her the sweetest support." (Mansfield Park, 2008: 92)

"A mesma circunstância que tinha levado Julia a ir embora, era para ela o apoio mais doce." (Mansfield Park, 2011: 125)

"The very first day that Morland came to us last Christmas — the very first moment I beheld him — my heart was irrecoverably gone." (Northanger Abbey, 2015: 71)

"O primeiro dia em que Morland nos visitou, no Natal, o primeiro momento em que o vi, meu coração tinha ido, irrecuperavelmente.” (Northanger Abbey, 2012: 91)

\footnotetext{
2 The choice for 3 novels by Jane Austen is due to the importance of her work to the consolidation of Modern English writing in Literature of the 19th century.
} 
Sentences (9) and (10) are also examples of non-canonical very. In (9), very modifies reason: they love life and in (10) tip of the egg. In (9) very was translated to simples 'simple' in the Portuguese version Mrs. Dalloway (1980) and in (10) it was translated to bem 'much, well' in The Great Gatsby (2011):

“...can't be dealt with, she felt positive, by Acts of Parliament for that very reason: they love life." (Mrs. Dalloway, 2000: 4)

“...impossível, ela o sabia, impossível salvá-las com leis parlamentares, por esta simples razão: amava a vida." (Mrs. Dalloway, 1980: 8)

"...my house was at the very tip of the egg, only fifty yards from the Sound..."

(The Great Gatsby, 1994: 11)

"Minha casa ficava bem na ponta do ovo, a menos de cinquenta metros do Estreito..."

(The Great Gatsby, 2011: 6)

When the translations to Portuguese are taken into consideration, it is noticeable that very is translated as mesma 'same', própria 'proper', simples 'simple' and bem 'much'. Curiously bem is also an intensifier in Portuguese (bem necessário - 'much needed' ${ }^{3}$ ). The importance of translations to this work is that they provide us a wider perception on how non-canonical very is interpreted. Thereby, the first conclusion is that there is a correlation between the canonical modification of very and its Portuguese version muito. However, non-canonical very is not captured by the same notion in Portuguese.

After a reflection on the data collected in the previous stages (The British National Corpus and the novels), we observed the presence of definite determiners, such as the definite article the, the demonstrative determiners this/that and the possessive ones his/her along with NPs modified by very. Strawson (1950) states that all these determiners encode a semantics of uniqueness. Coppock e Beaver (2015) also agrees with the notion of oneness as a semantic property of the article the. However, the notion of unique reference to defined phrases is a subject matter that had already been addressed by Russell (1905).

We observed the presence of definite determiners along with very and noticed that the NPs in our investigation indicate the presence of complex NPs. In this work, we assume the definition of Complex NPs (cf. Biber, Conrad, \& Leech, 2007) described as noun phrases modified by noun modifiers, such as premodifiers, which occur before the head noun, like attributive adjectives (e.g. a small house) or postmodifiers, which occur after the head noun, such as relative clauses (e.g. the house (which) I bought yesterday) and prepositional phrases (e.g. the house of my dreams), among others ${ }^{4}$. Our data indicate that the Complex NPs related to non-canonical very are the ones combined with postmodifiers. For instance, the very circumstance which had driven Julia away in (7), whereby the circumstance is modified by the relative clause which had driven Julia away.

After gathering these general properties of the distribution of non-canonical very, we proceed to the $3^{\text {rd }}$ stage of data collection which consists of controlled elicitation of contexts with the participation of a native English speaker of Wales. With the aim of verifying the proper cases in which very can modify NPs, the contexts created by us are based on our assumption of the semantic contribution of non-canonical very.

The controlled elicitation of contexts in this work is based on Mathewson's (2004) proposal. In this type of elicitation, we provide our consultant with contexts which we presume to be related to scenarios involving non-canonical very. Each context is equipped with 3 or 4 sentences so that the consultant is supposed to choose the sentences that he considers to be appropriate to the context given. The consultant is told about the possibility of choosing more than one sentence to each context, in case he considers it suitable. After choosing the proper sentences, the consultant is required to paraphrase them as our attempt to capture his interpretation to the meaning of non-canonical very.

Based on our data from The British National Corpus and the novels, we assumed that very modifies NPs with definite determiners and its modification with indefinite articles (a/an) or simply without determiners would potentially be inadequate. Although we had these clues, the absence of negative data was something we attempted to sort out with the controlled elicitation. We focused on the presence or absence of definite determiners, but we also paid close attention to the adequacy of Complex NPs along with non-canonical very. Here is important to highlight

3 For a description of bem see Quadros Gomes (2011) and Quadros Gomes \& Sanchez Mendes (2015).

${ }^{4}$ Biber, Conrad \& Leech (2007) also list other postmodifiers which we do not intend to go further here, such as to-infinitive clauses, ing-clause, ed-clauses and appositive noun phrases. 
that we also came up with inadequate sentences in order to check out syntactic adequacy, combining Mathewson's (2004) proposal for judgment of contexts with a grammaticality test, in order to observe sentences which probably would not be produced by a native English speaker. In (11), there is an example of one context created by us and the consultant response to it:

Context: You are 30 years old. You decide to visit the school where you used to go when you were a teenager. You enter a classroom and say:

( ) This is very classroom.

( ) This is the very classroom.

( ) This is a very classroom in which I had classes.

(x) This is the very classroom in which I had classes.

Paraphrase given: I have had classes in this very classroom while I was younger.

Having analyzed the consultant's response to contexts like (11), we could notice that non-canonical very seems to require definite DPs, insofar as neither the sentences without articles nor the sentences with indefinite articles were chosen. Moreover, we could also notice that the NP would need a complement to become more restricted in the context in which the sentence is delivered, as the role of the relative clause in which I had classes in This is the very classroom in which I had classes.

In respect with the paraphrase, even though the consultant made use of non-canonical very in I have had classes in this very classroom while I was younger, demonstrating that this type of modification is produced by a native English speaker, it does not enable us to fully understand his interpretation of non-canonical very. Probably, this behavior of the consultant might have occurred due to his caution of doing more than requested.

For better comprehension of the consultant's interpretation on the meaning of very, we elaborated a new stage of tests. We provided him with the same contexts from the first test. However, we only presented the sentence(s) chosen by the consultant in the first test. We explained that we would like to know his interpretation to very in the sentences and he should express it with the paraphrase. In (12), there is an example:

Context: You are 30 years old. You decide to visit the school where you used to go when you were a teenager. You enter a classroom and say: 'I have had classes in this very classroom while I was younger.'

Paraphrase given: 'I have had classes in this very classroom while I was younger' means I've had classes in this exact classroom while I was younger.

In summary, very is used with complex noun phrases forming definite DPs and have an interpretation that can sometimes be captured by exact, proper, same. Next sections will present formal analysis to this meaning. We will take into account all this properties in order to seek a unified analysis to very.

\section{Literature Review}

\subsection{Scalar Semantics}

The aim of this section is to present the scalar semantics adopted in this paper to analyze non-canonical very. Scalar semantics is a recent approach in Formal Semantics to degree modification (Kennedy, 1999; Kennedy and McNally, 2005). Scales are theoretical constructs that capture the notion of how certain linguistic phenomena can be graded in natural languages. They are sets of ordered degrees in a certain dimension than can be metaphorically conceptualized as a ruler. Take for instance the sentence in (13). In a scalar semantics it is analyzed as making a statement about the relation between John and the degree 2 meters in the stature scale.

\section{John is $\mathbf{2}$ meters tall.}

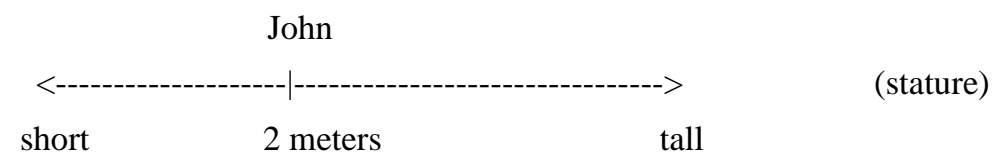

One way to formally implement this idea is considering that degrees (type d) are part of the semantic domain in the same way as individuals (type e), events (type s), and true values (type t). ${ }^{5}$ In this approach gradable adjectives such

5 We are adopting a type driven interpretation in the sense of Heim and Kratzer (1998). The only rule used in this paper in 
as tall denote a relation between individual and degrees (type $<\mathbf{d},<\mathbf{e}, \mathbf{t}>>)^{6}$ (15a) gives the lexical entry of tall in this proposal. (15b) offers the general formula for gradable adjectives. $\mathbf{m}_{\mathbf{g}}$ is the relevant dimension associated to the scale's adjective.

$$
\begin{aligned}
& \text { a. } \llbracket \text { tall } \rrbracket_{<\mathrm{d},<\mathrm{e}, \downarrow>}=\lambda \mathrm{d}_{\mathrm{d}} \lambda \mathrm{x}_{\mathrm{e}} \text {. "stature" }(\mathrm{x})=\mathrm{d} \\
& \text { b. } \llbracket A d j_{g} \rrbracket=\lambda \mathrm{d} \lambda \mathrm{x} . \mathrm{m}_{\mathrm{g}}(\mathrm{x})=\mathrm{d}
\end{aligned}
$$

The derivation of (15) is given below.

$$
\begin{aligned}
& \llbracket 2 \text { meters } \rrbracket_{\mathrm{d}}=2 \text { meters } \\
& \llbracket 2 \text { meters tall } \rrbracket_{<e, \downarrow>}=\llbracket \text { tall } \rrbracket(\llbracket 2 \text { meters } \rrbracket) \\
& \llbracket 2 \text { meters tall } \rrbracket_{<e, \downarrow>}=\lambda \mathrm{d} \lambda \mathrm{x} \text {. "stature" }(\mathrm{x})=\mathrm{d}(2 \text { meters }) \\
& \llbracket 2 \text { meters tall } \rrbracket_{<e, \downarrow>>}=\lambda \mathrm{x} . \text { "stature" }(\mathrm{x})=2 \text { meters }
\end{aligned}
$$

Scales are useful to treat sentences that make explicitly reference to degrees such as (13), and also to provide a proper analysis to comparatives and degree modification. In a seminal work, Kennedy \& McNally (2005) (henceforth K\&M) proposed that different logical properties of scales related to gradable predicates can have an influence on English grammar. They gave light to the study of the degree modifiers very, much and well modifying participle adjectives in English. According to K\&M, participles encode semantic properties that have an influence on their selections by these modifiers. For instance, in sentences (17a-c), there is the modification of the adjective behaved:

$$
\begin{aligned}
& \text { a. \# John is very behaved. } \\
& \text { b. \# John is much behaved. } \\
& \text { c. John is well-behaved. }
\end{aligned}
$$

The examples in (17a) and (17b) indicate that behaved is an predicate that cannot be modified by very or much. On the other hand, when it comes to the degree modifier well, the meaning of the sentence $(17 \mathrm{c})$ can be interpreted: there is a person who has a certain degree of behavior denoted by the degree modifier well. The restriction observed is associated to a feature associated to the participle. Behaved is a property that can be associated to a scale that is closed in its ends.

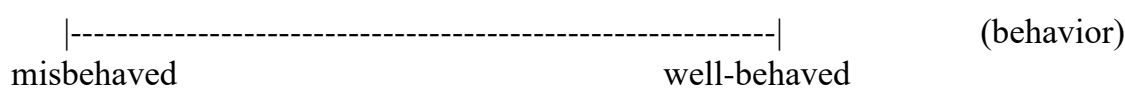

In (18), there is a scale (the set of ordered degrees) of behavior closed at both endpoints, one associated to misbehavior and one associated to good behavior. There is, once an individual is considered well-behaved, it cannot be related to a higher degree of behavior. The same can be said for misbehaved. Thus, according to K\&M, well is a degree modifier that selects totally-closed scale predicates.

A scalar description is also provided by K\&M for much in order to explore its semantic properties in terms of semantic selection, as shown by the sentences in (19):

$$
\begin{aligned}
& \text { a. \# This is a very needed action. } \\
& \text { b. This is a much needed action. } \\
& \text { c. \# This is a well needed action. }
\end{aligned}
$$

Both sentences (19a) and (19c) are examples that illustrate cases of semantic restrictions related to degree modification. In (19a), very does not modify the participle adjective needed, similarly to (19c), whereby well does not modify needed. On the other hand, in (19b), the truth conditions of the modification of much on needed can be interpreted: there is a highly necessary action. In (20), there is the representation of the scale of necessity. This scale is closed at its lower endpoint, but open at its upper endpoint, which means that needless stands for $0 \%$ of necessity on the scale, whereas any other value different from $0 \%$ qualifies something as necessary. Thus, K\&M's scale proposal to much indicate that it is a degree modifier which selects partially-closed adjectival scales.

Functional Application.

6 We are assuming Kennedy and McNally (2005) and considering that the measure function is part of gradable adjectives. This is not the only way to formalize gradable adjectives. In Kennedy $(1999,2007)$, for instance, adjectives denote measure functions of type $<\mathrm{e}, \mathrm{d}>$. An adjective such as tall denote $\lambda x$. "stature" $(x)$ in this approach. 


$\begin{array}{ll}\mid-1 & \\ 0 \% & \text { Value }>0 \% \\ \text { needless } & \text { needed } \rightarrow\end{array}$

Regarding canonical very, $\mathrm{K} \& \mathrm{M}$ also proposes that its semantic adequacy in sentences selecting predicates is related to scalar properties. Sentences in (21) illustrate its distribution:
a. This is very interesting.
b. \# This is much interesting.
c. \# This is well interesting.

Sentences (21b) and (21c) indicate that interesting is an adjective which cannot be modified by much or well. In terms of scales, interesting is a predicate that does not fit the necessary conditions required by much (partially-closed scale) or well (totally-closed scale). Interesting is an open-scale adjective, as shown in (22). There is a scale of interest varying from less to more interested that leaves open the possibility of being more and more or less and less interested.

$$
\text { less interested more interested (interest) }
$$

In this case, the modification of very in very interesting indicates an operation in which very boosts the degree of interest on the scale. The same can be sad about cases with adjectives. Although K\&M's proposal is an analysis for participles, they expand it to other types of open-scale adjectives, such as tall in (23):

(23) John is very tall.

In (23), very boosts the degree of the adjective tall to a degree above the standard of comparison, which can be considered the normal standard. For example, if we consider a context in which $1,70 \mathrm{~m}$ is the normal standard and John is 1,90 meter-height, so one might say that John is very tall in this context. However, when the context is related to basketball players whose standard of comparison is $2 \mathrm{~m}$, John is not considered tall. Thus, this example demonstrates that open-scale adjectives are context dependent on a comparison class ${ }^{7}$, which makes them relative gradable adjectives.

When it comes to gradable adjectives which do not fit the conditions proposed for canonical very by $\mathrm{K} \& \mathrm{M}$, there is a clash, as shown by the example (24):

(24) ? The glass is very empty/full.

Example (24) indicates that empty/full are adjectives that cannot be modified by very. ${ }^{8}$ This restriction is associated to the nature of the scale related to these adjectives. Empty and full compose a closed scale of capacity. This way, if one states that the glass is empty, it means that the glass is at the minimum degree of its capacity, whereas the glass is full means that the glass is at the maximum degree of its capacity. In summary, it is not necessary to take a comparison class into account to interpret the meaning of these sentences. K\&M consider adjectives that share the same properties of empty/full as absolute gradable adjectives.

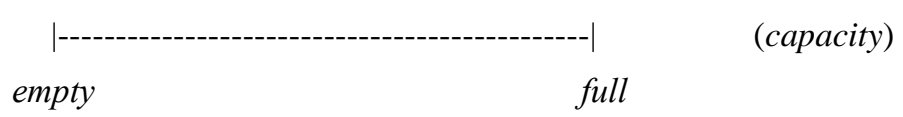

The same can be said about partially closed scales such as needed. An adjective that show the scalar property of this participle is dirty. In this case the comparison is also given by the nature of the scale. Then this is also an absolute predicate.

$$
\begin{array}{ll}
0 \% & \text { Value }>0 \% \\
\text { clean } & \text { dirty } \rightarrow
\end{array}
$$

Therefore, this section presented the nature of 3 different scales proposed by K\&M for the modification of gradable predicates. In sentences without modification, in turn, the scalar nature must also influence the interpretation of the

\footnotetext{
${ }^{7}$ Objects that share similar properties to whatever is being discussed (Klein 1980).

8 The only way to do so is to make a relative use of these adjectives, such as The restaurant is very empty these days in which empty is used considering a normal occupation of the restaurant not its absolute minimum and maximum capacity.
} 
sentence. A sentence with a relative/open-scale adjective such as John is tall must also manipulate a degree associated to a standard of comparison (like the sentence with very discussed above). Sentences with absolute/(partially-)closed predicates on the other hand handles with degrees that are present in their own scales.

One way to formally capture this difference in sentences without modification is assuming that a silent morpheme pos applies to gradable predicates of type $<\mathrm{d},<\mathrm{e}, \mathrm{t}\rangle>$ to form individual predicates of type $<\mathrm{e}, \mathrm{t}>$ and to provide the proper interpretation based on the standard and the scales degrees. We propose that pos has the following lexical entry (based on Kennedy, 2004 and adapted for a gradable predicate of type $<\mathrm{d},<\mathrm{e}, \mathrm{t}>>$ ). ${ }^{9}$

$$
\llbracket p o s \rrbracket=\lambda \mathrm{G}_{<\mathrm{d},<\mathrm{e}, \triangleright>>} \lambda \mathrm{x} . \exists \mathrm{d}\left[\mathrm{G}(\mathrm{d})(\mathrm{x}) \& \mathrm{~d} \geq \mathrm{d}_{\text {stand-out }}\right]
$$

The degree $\mathbf{d}_{\text {stand-out }}$ is the relevant degree according to the type of the scale and is defined according to the following.

$$
\mathrm{d}_{\max }\left(\mathrm{m}_{\mathrm{g}}\right) \text { if } \max \left(\mathrm{m}_{\mathrm{g}}\right) \text { is defined }
$$

$\mathrm{d}_{\text {stand-out }}\left\{\mathrm{d}_{\min }\left(\mathrm{m}_{\mathrm{g}}\right)\right.$ if $\min \left(\mathrm{m}_{\mathrm{g}}\right)$ is defined

$\mathrm{d}_{\mathrm{std}}\left(\mathrm{m}_{\mathrm{g}}\right)$ elsewhere

$\mathrm{m}_{\mathrm{g}}=$ dimension

Kennedy (2007) proposes an Interpretive Economy that combined with the description above ensures that the relevant scalar information encoded in the adjective lexicon is considered.

Interpretive Economy:

Maximize the contribution of the conventional meanings of the elements of a sentence to the computation of its truth conditions.

(Kennedy 2007, 36)

Examples in (30) show how Interpretive Economy is implemented in open (30a) and closed (30b) scales predicates. In open scales the $\mathbf{d}_{\text {std }}$ of the scale is selected whereas in closed scales the maximum degree in attained.

$$
\begin{array}{ll}
\text { a. } & \llbracket \text { tall } \rrbracket=\lambda \mathrm{d} \lambda \mathrm{x} . ~ " \text { stature" }(\mathrm{x})=\mathrm{d} \\
\text { a'. } & \left.\llbracket \text { pos } \rrbracket(\llbracket \text { tall } \rrbracket)=\lambda \mathrm{x} . \exists \mathrm{d}\left[\text { "stature" }(\mathrm{x})=\mathrm{d} \& \mathrm{~d}>\mathrm{d}_{\text {std }} \text { (stature }\right)\right] \\
\text { b. } & \llbracket \text { full } \rrbracket=\lambda \mathrm{d} \lambda \mathrm{x} . \text { "fullness" }(\mathrm{x})=\mathrm{d} \\
\text { b'. } & \llbracket \text { pos } \rrbracket(\llbracket \text { full } \rrbracket)=\lambda \mathrm{x} . \exists \mathrm{d}\left[\text { [fullness" }(\mathrm{x})=\mathrm{d} \& \mathrm{~d}=\mathrm{d}_{\max }\right. \text { (fullness) ] }
\end{array}
$$

Then, a sentence like Jonh is tall has the following semantic derivation:

$$
\begin{aligned}
& \llbracket \text { tall }_{\text {pos }} \rrbracket_{<\mathrm{e}, \triangleright}=\lambda \mathrm{x} . \exists \mathrm{d}\left[\text { "stature" }(\mathrm{x})=\mathrm{d} \& \mathrm{~d}>\mathrm{d}_{\text {std }}(\text { stature })\right] \\
& \llbracket J \text { ohn is tall } \rrbracket_{\mathrm{t}}=\lambda \mathrm{x} . \exists \mathrm{d}\left[\text { "stature" }(\mathrm{x})=\mathrm{d} \& \mathrm{~d}>\mathrm{d}_{\text {std }}(\text { stature })\right](\text { John }) \\
& \llbracket \text { John is tall } \rrbracket_{\mathrm{t}}=1 \text { sse } \exists \mathrm{d}\left[\text { "stature" }(\mathrm{John})=\mathrm{d} \& \mathrm{~d}>\mathrm{d}_{\text {std }}(\text { stature })\right]
\end{aligned}
$$

In words, John is tall is true if there is a degree $\mathbf{d}$ associated to the stature of John that is higher than a standard degree $\mathbf{d}_{\text {std }}$ of the stature dimension.

This section introduced how logical differences on scales associated to gradable predicates can influence the grammar of a language and one way to provide a proper formal treatment to this contrast. In the next section we will present a proposal to very that takes into account its canonical use as a degree intensifier of open-scale adjectives with relative standard as a starting point to the analysis of non-canonical very.

\section{A proposal for Very}

This section presents our proposal for very based on a scalar semantics (Kennedy \& McNally, 2005, Doetjes 2008). The analysis assumes two main steps: (i) very has a unified meaning and the interpretation of the modified sentence depends on the modified predicate; and (ii) the scale modified by non-canonical very is closed and contextually defined. The interpretation of exhaustivity is derived by the combination of these steps as a sub-product of the modification. Each of the subsections below details these steps.

\subsection{The Unified Contribution of Very}

According to Quadros Gomes and Sanchez-Mendes (2015), degree modification can be affected by the scalar nature

9 Kennedy (2004) assumes the lexical entry of gradable adjectives of being of type $<e, d>$. 
of the modified phrase in 3 ways: (i) the scalar nature of the modified phrase determines the distribution of degree modifiers, such as very, much and well in English (K\&M); (ii) the scalar nature of the modified phrase determines the output meaning of the modified phrase, such in sentences with pita(t) in Karitiana; and (iii) the scalar nature of the modified phrase determines the properties of the whole modified phrase such as in the case of muito, bem and well in Brazilian Portuguese.

In order to give an appropriate analysis to very we assume that the product of a modified phrase can have different interpretations according to the predicate under modification (cf. Sanchez-Mendes, 2015; Quadros Gomes \& Sanchez-Mendes, 2015 for pita $(t))$.

In Karitiana, for example, the same modifier pita can be applied to open and to closed scales predicates with different effects. When it is applied to open scale adjectives it boosts the degree of the scale above the normal (as the canonical very in English) (32a). When it is applied to closed scales it attains the maximum degree (as completely in English) (32b).

\begin{tabular}{|c|c|c|c|c|}
\hline (32) a. & $\begin{array}{l}\text { Õwã } \\
\text { boy }\end{array}$ & $\begin{array}{l}\text { se'a } \\
\text { good }\end{array}$ & $\begin{array}{l}\text { pita } \mathrm{i} \text {-otam- } \varnothing . \\
\text { pita } \text { PART-arrive-ABS }\end{array}$ & KARITIANA \\
\hline & 'The ver' & good bo & arrived' & \\
\hline b. & Karamã & & pita i-pot- $\varnothing$. & \\
\hline
\end{tabular}

'The completely open door broke' $\quad$ (Sanchez-Mendes, 2015: 70)

In order to capture this property, Sanchez-Mendes (2015) offered a unified lexical entry to pita similar to pos morpheme (cf. Kennedy, 2007) discussed in the previous section and assign its differences of interpretations to the scalar properties of the modified predicate. Based on Kennedy's (2007) proposal, the proper reading in (33) is derived by the standard-fixing function $\mathbf{s}$ that varies according to the properties encoded by the modified adjective and fixes the degree $\mathbf{d}_{\mathbf{s}}$.

$$
\llbracket \text { pita } \rrbracket=\lambda \mathrm{G} \lambda \mathrm{x} . \exists \mathrm{d}\left[\mathrm{G}(\mathrm{d})(\mathrm{x}) \& \mathrm{~d} \geq \mathrm{d}_{\mathrm{s}}\right]
$$

(Sanchez-Mendes, 2015: 70)

Our analysis of very goes in the same direction. First, we assume that very has the semantics suggested by K\&M, namely that the difference, for example, between John is tall and John is very tall is that the relative standard of the former sentence is further boosted. A way to implement this is considering that very takes the pos $+A$ individuals as a comparison class (cf. K\&M).

$$
\llbracket v e r y \rrbracket^{C}=\lambda \mathrm{G} \lambda \mathrm{x} . \exists \mathrm{d}\left[\operatorname{standard}(\mathrm{d})(\mathrm{x})\left(\lambda \mathrm{y} \cdot \llbracket \operatorname{pos}(\mathrm{G})(\mathrm{y}) \rrbracket^{C}\right) \quad \& \mathrm{G}(\mathrm{d})(\mathrm{x})\right]
$$

Kennedy \& McNally (2005: 370)

K\&M leaves open how standard can be defined in their proposal. In order to capture how it can be defined, we assume Kennedy's $(2004,2007)$ proposal to pos morpheme to give a proper semantics for very that will be useful to derive its readings on step 2 (cf. Sanchez-Mendes, 2015 for Karitiana). Based on the pos lexical entry assumed before we present the following lexical entry to very.

$$
\llbracket \text { very } \rrbracket=\lambda \mathrm{G} \lambda \mathrm{x} . \exists \mathrm{d}\left[\mathrm{G}(\mathrm{d})(\mathrm{x}) \& \mathrm{~d} \geq \mathrm{d}_{\text {stand-out }}\right]
$$

This is identical to $p o s$ in (27) except for the following definition of $\mathrm{d}_{\text {stand-out: }}$

$$
d_{\text {std }}\left(m_{g}\right) \text { in its canonical use with relative adjectives }
$$

$\mathrm{d}_{\text {stand-out }}=\left\{\mathrm{d}_{\max }\left(\mathrm{m}_{\mathrm{g}}\right)\right.$ if $\max \left(\mathrm{m}_{\mathrm{g}}\right)$ can be defined on a predicate

It is important to mention that the application of very on a closed scale $\max \left(\mathbf{m}_{\mathbf{g}}\right)$ is different from its relative uses in cases such as very full discussed in K\&M. As it will be developed in the next section, we are assuming that non-canonical very has a true absolute meaning in its non-canonical use.

Notice that this is also different from attributing the maximum degree attachment in the meaning of the modifier, such as completely. We are offering an analysis that considers the contribution of the predicate under modification to derive the proper use of the modified phrase compositionally.

$$
\llbracket \text { completely } \rrbracket=\lambda \mathrm{G} \lambda \mathrm{x} . \exists \mathrm{d}\left[\mathrm{d}=\max \left(\mathrm{S}_{\mathrm{G}}\right) \& \mathrm{G}(\mathrm{d})(\mathrm{x})\right]
$$




\subsection{Scales Modified by Non-canonical 'Very'}

The second step of our analysis consists of associating a closed scale to NPs that are not lexically gradable and are modified by non-canonical very. ${ }^{10}$ Despite being a contextual correlation, this is based on the type of scales that can be associated to different types of grammatical classes. According to Doetjes (2008), open scales are an attribute exclusive of adjectives. Other predicates such as NPs and VPs are typically associated to closed scales. The relation of NPs and VPs with a "zero" reading (38) bases them like lower closed scale predicates.

$$
\begin{aligned}
& \text { a. John read no books. (no books = zero books) } \\
& \text { b. John did not read. ('zero' reading by John) }
\end{aligned}
$$

(Doetjes, 2008: 152)

Notice the difference between (38) and (39). Since tall is an open scale adjective and has a relative standard, (39a) is not contradictory. John has some degree on the scale of stature and can be compared to the standard degree of the scale and with other individuals. Differently from the examples in (38), there is no "zero" degree in the stature scale. (39b) on the other hand has an absolute standard determined by the minimum degree, then the object must have a non-zero degree of the property or it cannot be applied. Similarly, in (39c), the modified scale is determined by the minimum degree of appreciation involved in the verbal predicate to appreciate hence the sentence is also odd.

$$
\begin{aligned}
& \text { a. John is not tall, but he is taller than Peter. } \\
& \text { b. \#This towel is not wet but is its wetter than that one. } \\
& \text { c. \#John did not appreciate the movie, but he appreciated it more than Peter did. }
\end{aligned}
$$

(Doetjes, 2008: 153)

Assuming Doetjes's (2008) proposal that closed scales are found both in adjectival and other domains such as NPs we propose that they are found in non-canonical uses of very. We take NPs modified by very to be associated to an absolute standard determined by not only a minimum (similarly to what was sad about NPs in (38a)), but also by a maximum degree. NPs can then be associated to a 0-1 scale involved in an identity operation. Recall that the difference between dstd and dmax in (36) induce the difference between greater than $(>)$ and equals to $(=)$. Crucially in the case of NPs combined with very we have a closed scale involved in an identity operation.

We propose then that very has a semantic and a pragmatic use. This is in accordance with Sawada (2018) that noted that pragmatic scalar modifiers usually perform a "dual use", one semantic (at-issue) and one pragmatics (not-at-issue). We will not go deep on the pragmatical composition of very on the direction of Sawada (2018). We just assume that a pragmatical use can be found in some degree modifiers. Specially in the case of very, the pragmatic nature concerns the possibility of complex NPs that are not lexically gradable of being contextually associated to a closed scale.

In this sense very is similar to totally in English, an intensifier that is also engaged in a commitment/precision use. In its semantic use totally selects a specific type of adjective, an upper-bounded scale predicate and it encodes the same content as completely (40a) (K\&M). On its pragmatic use (40b) it is applied to the proposition level and strengths the speaker's engagement to the utterance and expresses something like unquestionably (Beltrama, 2018).

\section{a. The bus is totally full.}

b. You should totally click on that link! It's awesome.

However, very and totally differ in the sense that totally attaches to isomorphic scales on the semantic and pragmatic domains. The maximum degree available by the lexicon in (40a) is mapped in the universal quantification proposed to capture the speaker's commitment on the pragmatic level (cf. Beltrama, 2018). Very on the other hand acts on different types of scales according to each domain. It attaches to open scales on the semantic domain (K\&M) and on closed ones on its pragmatic use according to our proposal. Besides, totally is attached to a scale related to the speaker's commitment and it is, then, a propositional level modifier. Very, on the other hand, has a narrower scope and indicates a property of the individual denoted by the NP. Next section shows how this formally works putting the 2 steps together.

\subsection{Putting the 2 Steps Together}

\footnotetext{
${ }^{10}$ We are considering that the order of semantic composition follows the word order: definite article (very (complex NP)). Any other proposal would have to deal with linearization.
} 
This section shows how the steps suggested above can adequately derive the interpretation of sentences of both canonical and non-canonical very. We are going to show how a unified lexical entry such as the one proposed in (41a) $[=(35)]$ works with both adjectives and NPs.

$$
\text { a. } \llbracket \text { very } \rrbracket=\lambda \mathrm{G} \lambda \mathrm{x} . \exists \mathrm{d}\left[\mathrm{G}(\mathrm{d})(\mathrm{x}) \& \mathrm{~d} \geq \mathrm{d}_{\text {stand-out }}\right]
$$

b. A more specific version for (36)

$$
\begin{aligned}
& d_{s t d}\left(m_{g}\right) \text { in its canonical use with relative adjectives } \\
& m_{g} \text { is lexically defined by the adjective } \\
& d_{\max }\left(m_{g}\right) \text { if } \max \left(m_{g}\right) \text { can be defined on a predicate } \\
& m_{g} \text { is contextually defined by the NP }
\end{aligned}
$$

First, (43) illustrates the derivation of canonical very modifying a relative adjective.

$$
\begin{aligned}
& \text { John is very tall. } \\
& \llbracket \text { very tall } \rrbracket_{<\mathrm{e}, \triangleright}=\llbracket \text { very } \rrbracket(\llbracket \text { tall } \rrbracket) \\
& \llbracket \text { very tall } \rrbracket_{<\mathrm{e}, \triangleright}=\lambda \mathrm{G} \lambda \mathrm{x} . \exists \mathrm{d}\left[\mathrm{G}(\mathrm{d})(\mathrm{x}) \& \mathrm{~d} \geq \mathrm{d}_{\text {stand-out }}\right](\lambda \mathrm{d} \lambda \mathrm{x} \text {. "stature" }(\mathrm{x})=\mathrm{d}) \\
& \llbracket \text { very tall } \rrbracket_{<\mathrm{e}, \triangleright}=\lambda \mathrm{x} . \exists \mathrm{d}\left[\lambda \mathrm{x} \text {. "stature" }(\mathrm{x})=\mathrm{d} \& \mathrm{~d}>\mathrm{d}_{\mathrm{std}}(\text { stature })\right] \\
& \llbracket J \text { John is very tall } \rrbracket_{\mathrm{t}}=\lambda \mathrm{x} . \exists \mathrm{d}\left[\lambda \mathrm{x} \text {. "stature" }(\mathrm{x})=\mathrm{d} \& \mathrm{~d}>\mathrm{d}_{\text {std }}(\text { stature })\right](\text { John }) \\
& \llbracket J \text { ohn is very tall } \rrbracket_{\mathrm{t}}=1 \text { sse } \exists \mathrm{d}\left[\text { "stature" }(\mathrm{John})=\mathrm{d} \& \mathrm{~d}>\mathrm{d}_{\text {std }}(\text { stature })\right]
\end{aligned}
$$

In words, John is very tall is true if there is a degree $\mathbf{d}$ associated to the stature of John that is higher than a standard degree $\mathbf{d}_{\text {std }}$ associated to the stature dimension in the context.

Now turning to the derivation of non-canonical very in (44) in which the DP encodes, for example, that there is a unique house in the context in which John lived in when he was younger.

(44) I saw [ the very house John lived in ].

The first obvious obstacle in this derivation is that even if we assume that very can be associated to different types of predicates as it is stated in (41b), the NP house John lived in is a predicate of individual of type $<\mathrm{e}, \mathrm{t}\rangle$ and has no degree variable.

$$
\llbracket \text { very house John lived in } \rrbracket=\llbracket \text { very } \rrbracket(\llbracket \text { house John lived in } \rrbracket)
$$

undefined - type mismatch

In order to solve this kind of type mismatch, we follow Sanchez-Mendes's (2014) type-shifting rule Degnoun that takes predicates of type $\langle\mathrm{e}, \mathrm{t}\rangle$ and gives a gradable predicate of type $\langle\mathrm{d},<\mathrm{e}, \mathrm{t}\rangle\rangle$ associated to a precision dimension (following Morzycki, 2011; Masià, 2013).

$$
\llbracket D e g_{\text {NOUN }} \rrbracket=\lambda \mathrm{P}_{<\mathrm{e}, \triangleright} \lambda \mathrm{d} \lambda \mathrm{x} . \mathrm{P}(\mathrm{x}) \& \text { "precision }_{\mathrm{P}} \text { " }(\mathrm{x})=\mathrm{d}
$$

Crucially we are adapting this function to very assuming that precision is taken to be a $0-1$ closed scale that is not lexically available but is contextually determined. Its pragmatic counterpart lies in the way this precision is interpreted in each situation. This goes in hand with the fact that very modifies complex NPs that help enriching the context and

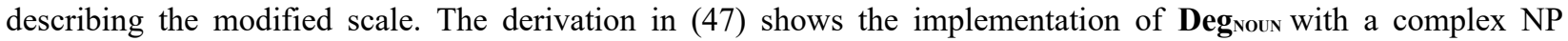
modified by non-canonical very.

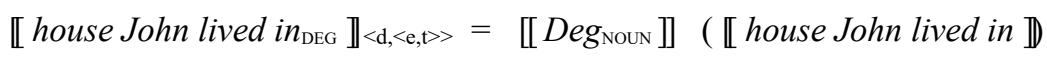

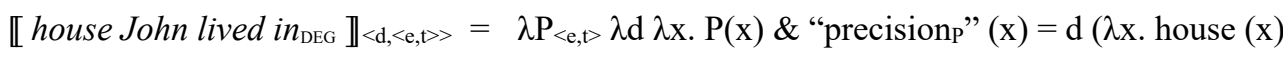

$$
\begin{aligned}
& \text { \& lived-in (x) (John)) }{ }^{11} \\
& \llbracket \text { house John lived i } n_{\mathrm{DEG}} \rrbracket_{<\mathrm{d},<\mathrm{e}, \triangleright>}=\lambda \mathrm{d} \lambda \mathrm{x} \text {. house }(\mathrm{x}) \& \text { lived-in }(\mathrm{x})(\mathrm{John}) \& \text { "precision }{ }_{\text {house }} \text { " }(\mathrm{x})=\mathrm{d}
\end{aligned}
$$

Now very can be applied on the gradable version of the NP turning it to a predicate of individuals to be attached by the determiner.

$$
\begin{aligned}
& \llbracket \text { very house John lived in } \rrbracket_{<e, \downarrow}=\llbracket \text { very } \rrbracket\left(\llbracket \text { house John lived in } \rrbracket_{<\mathrm{d},<\mathrm{e}, \downarrow>}\right) \\
& \llbracket \text { very house John lived in } \rrbracket_{<\mathrm{e}, \triangleright}=\lambda \mathrm{G} \lambda \mathrm{x} . \exists \mathrm{d}\left[\mathrm{G}(\mathrm{d})(\mathrm{x}) \& \mathrm{~d} \geq \mathrm{d}_{\text {stand-out }}\right](\lambda \mathrm{d} \lambda \mathrm{x} \text {. house }(\mathrm{x}) \& \text { lived-in }(\mathrm{x})(\mathrm{John})
\end{aligned}
$$

\footnotetext{
11 For sake of simplicity we are ignoring tense and aspect in the denotation.
} 


$$
\begin{aligned}
& \& \text { "precision } \\
& \text { house" }(\mathrm{x})=\mathrm{d}) \\
& \llbracket \text { very house John lived in } \rrbracket_{<\mathrm{e}, \triangleright}=\lambda \mathrm{x} . \exists \mathrm{d}[\text { house }(\mathrm{x}) \& \text { lived-in }(\mathrm{x})(\mathrm{John}) \& \text { "precision } \text { house } \text { " }(\mathrm{x})=\mathrm{d} \\
& \left.\& \mathrm{~d}=\mathrm{d}_{\max }\right]
\end{aligned}
$$

(49) shows the derivation of the DP.

$$
\begin{aligned}
& \llbracket \text { the very house John lived in } \mathbb{\sharp}=\llbracket \text { the } \rrbracket(\llbracket \text { veryhouse John lived in } \rrbracket) \\
& \llbracket \text { the very house John lived in } \mathbb{k}_{\mathrm{k}}=\lambda \mathrm{f} \text {. the unique } \mathrm{x} \text { for which } \mathrm{f}(\mathrm{x})=1(\lambda \mathrm{x} . \exists \mathrm{d}[\text { house }(\mathrm{x}) \& \text { lived-in }(\mathrm{x})(\mathrm{John}) \\
& \text { \& "precision } \left.\text { house } \text { " }(\mathrm{x})=\mathrm{d} \& \mathrm{~d}=\mathrm{d}_{\max }\right]^{12} \\
& \text { [I the very house John lived in } \mathbb{k}=\text { the unique } \mathrm{x} \text { for which } \exists \mathrm{d}[\text { house (x) \& lived-in (x) (John) } \\
& \text { \& “precision } \left.\text { house" } \text { ( } \mathrm{x})=\mathrm{d} \& \mathrm{~d}=\mathrm{d}_{\max }\right]
\end{aligned}
$$

In words, the DP the very house John lived in denotes the unique $\mathbf{x}$ for which $\mathbf{x}$ is a house, John lived in $\mathbf{x}$, and $\mathbf{x}$ is associated to a degree $\mathbf{d}$ that is maximum is a contextual scale of precision associated to $\mathbf{x}$.

We consider that the joint of the semantics of the definite article and the contribution of the maximum degree in a scale enriched by modification of the NP generates exhaustivity as a sub-product. That is why the speaker paraphrased sentences with non-canonical very considering that the DP in case denotes a unique individual (or group) and discards other possibilities.

This section showed a proposal to non-canonical very based on its canonical denotation. Scalar semantics enabled an unified analysis based on logical properties of the scales associated to the modified predicates. The analysis presented support the general idea that scalar properties are relevant to the compositional computation of the meaning of sentences with degree modifiers.

\section{Conclusion}

In this paper we analyze the use of non-canonical very. Firstly, we presented and explained the three methodological steps involved in our data collection exemplifying sentences with non-canonical very. As described, we selected sentences from The British National Corpus and from some British and American novels written in the $19^{\text {th }}$ and $20^{\text {th }}$ centuries that helped us proceed to the third step which was the controlled elicitation of contexts with the participation of a native speaker of Wales. Our data indicate that non-canonical very modifies definite DPs with complex NPs.

We offered an analysis for non-canonical very not focusing on its difference with the canonical intensifier but on their similarity. We were very much inspired by an intuition that was beautifully captured by Beltrama (2018): "An outstanding issue concerns the relationship between the lexical and the pragmatic use, and in particular whether, beneath their obvious differences, the two flavors of the intensifier still share a semantic kernel." (Beltrama, 2018, 37).

We left open some important questions though. The first concerns on how the pragmatic nature can be compositionally captured. We incorporated the context in a precision scale that could be better developed in other terms. One could argue for example in favor of an analysis on the line of conventional implicatures (cf. Potts, 2005 and Sawada, 2018). The second is on the proper role of definite determiners that attach to NPs modified by non-canonical very. It is not clear if they have the same presuppositional function as nonmodified version (e.g. the house John lived in). If very selects a maximum degree by an identity operation providing a unique element on the contextual scale, it remains open what is the precise operation performed by the definite article in phrases like this. The answer can either assume that definite articles are expletives in phrases with non-canonical very (cf. Longobardi, 1994) or either consider it is related to exhaustivity as a conventional meaning rather than a sub-product as it was interpreted in this paper. These are all topics for further research.

\section{References}

Austen, J. (1996). Orgulho e preconceito / Maria Francisca Ferreira de Lima (translator). Mem Martins: Europa-América, D. L. 1996. (PDF). Retrieved September 9th, 2017, from http://static.recantodasletras.com.br/arquivos/2196784.pdf

Austen, J. (2005). Pride and Prejudice. (PDF). Retrieved September 9th, 2017, from

12 We are adopting a very simple notion of the definite article. Please see Heim \& Kratzer (1998) and the works cited in it for discussion. 
https://doi.org/10.5117/9781904633013

Austen, J. (2008). Mansfield Park. Project Gutenberg, (PDF). Retrieved December 18th, 2017, from https://www.gutenberg.org/files/141/141-pdf.pdf

Austen, J. (2011). Mansfield Park. Mariana Menezes Neumann (translator). Rio de Janeiro: Grupo Editorial Record.

Austen, J. (2012). Northanger Abbey. Eduardo Furtado (translator). São Paulo: Editora Landmark, (PDF). Retrieved December 20th, 2017, from http://sanderlei.com.br/PDF/Jane-Austen/Jane-Austen-A-Abadia-De-Northanger.pdf

Austen, J. (2015). Northanger Abbey. Published by Gothic Digital Series @UFSC. (PDF). Retrieved December 18th, 2017, from

https://repositorio.ufsc.br/bitstream/handle/123456789/173242/Northanger\%20Abbey.pdf?sequence=1\&isAllo wed $=\mathrm{y}$

Baugh, A. C., \& Cable, T. (2002). A History of the English Language. London: Routledge.

Beltrama, A. (2018). Totally between subjectivity and discourse: Exploring the pragmatic side of intensification. Journal of Semantics, 35, 219-261. https://doi.org/10.1093/semant/ffx021

Beltrama, A., \& Bochnak, M. R. (2015). Intensification without degrees cross-linguistically. Natural Language \& Linguistic Theory, 33(3), 843-879. https://doi.org/10.1007/s11049-015-9294-8

Biber, D., Conrad, S., \& Leech, G. (2007). Longman Grammar of Spoken and Written English (6th ed.). Harlow: Pearson Education Limited.

Bylinina, L., \& Sudo, Y. (2015). Varieties of intensification: Remarks on Beltrama and Bochnak 'Intensification without degrees cross-linguistically'. Natural Language Linguistic \& Theory, 33, 881-895. https://doi.org/10.1007/s11049-015-9291-y

Cappock, E., \& Beaver, D. (2015). Definiteness and determinacy. Linguistics and Philos, 38(5), 377-435. https://doi.org/10.1007/s10988-015-9178-8

Crystal, D. (2008). A Dictionary of Linguistics and Phonetics (6th ed.). Oxford: Blackwell Publishing. https://doi.org/10.1002/9781444302776

Doetjes, J., \& Adjectives and degree modification. (2008). In: MCNALLY, L.; KENNEDY, C. (eds.) Adjectives and adverbs: syntax, semantics and discourse. Oxford: Oxford University Press, 123-155.

Fitzgerald, F. S. (1994). The Great Gatsby. London: Penguin.

Fitzgerald, F. S. (2011). The Great Gatsby. William Lagos (translator). L\&PM Pocket, (PDF). Retrieved January 17th, 2018 , from https://esadmacommunication.files.wordpress.com/2017/02/f-scott-fitzgerald-o-grande-gatsby.pdf

Heim, I., \& Kratzer, A. (1998). Semantics in Generative Grammar. Massachusetts: Blackwell Publishers.

Kennedy, C. (1999). Projecting the adjective: The syntax and semantics of gradability and comparison. New York: Garland.

Kennedy, C. (2004). Towards a grammar of vagueness. Draft of a paper given at the 2003 Princeton Semantics Workshop.

Kennedy, C. (2007). Vagueness and grammar: The semantics of relative and absolute gradable adjectives. Linguistics and Philosophy, 30(1), 1-45. https://doi.org/10.1007/s10988-006-9008-0

Kennedy, C., \& Mcnally, L. (2005). Scale Structure, Degree Modification, and the semantics of Gradable Predicates. Language, 81(2), 345-381. https://doi.org/10.1353/lan.2005.0071

Klein, E. (1980). A semantics for positive and comparative adjectives. Linguistics and Philosophy, 4, 1-45. https://doi.org/10.1007/BF00351812

Longobardi, G. (1994). Reference and proper names: a theory of movement in syntax and LF. Linguistic Inquiry, 25, 609-665.

Masià, M. (2013). What veracity does to imprecision: the case of Spanish verdadero Proccedings of ESSLLI 2013 Student Session. Düsseldorf, Germany.

Matthewson, L. (2004). On the Methodology of Semantic Fieldwork. International Journal of American Linguistics, 
70, 369-415. https://doi.org/10.1086/429207

Mcnally, L. (2016). Modification. M. Aloni \& P. Dekker (eds.) Cambridge Handbook of Formal Semantics. Cambridge: Cambridge University Press, 442-466. https://doi.org/10.1017/CBO9781139236157.016

Mcnally, L., \& Kennedy, C. (2008). Introduction: adjectives and degree modification. In: MCNALLY, L.; KENNEDY, C. (eds.) Adjectives and adverbs: syntax, semantics and discourse. Oxford: Oxford University Press, 1-15.

Morzycki, M. (2011). Metalinguistic comparison in an alternative semantics for imprecision. Natural Language Semantics, 19(1), 39-86. https://doi.org/10.1007/s11050-010-9063-5

Potts, C. (2005). The Logic of Conventional Implicatures. Oxford: Oxford University Press. https://doi.org/10.1093/acprof:oso/9780199273829.001.0001

Quadros Gomes, A. P. (2011). Uma proposta de distinção semântica para os intensificadores 'muito’ e ‘bem'. Estudos Linguísticos (São Paulo. 1978), 40, 379-394.

Quadros Gomes, A. P., \& Sanchez-Mendes, L. (2015). Degree modification in Brazilian Portuguese and in Karitiana. Revista Virtual de Estudos da Linguagem, 13, 5-32.

Russel, B. (1905). On Denoting. Mind (New Series), 14(56), 479-493. https://doi.org/10.1093/mind/XIV.4.479

Sanchez-Mendes, L. (2015). Degree Modification in Karitiana: Evidence for Scalar Properties of Gradable Predicates. In: PASQUEREAU, J. C. (Ed.) SULA 8: Proceedings of the Eighth Meeting of the Semantics of Under-Represented Languages in the Americas. Amherst: GLSA Publications, 53-72.

Sawada, O. (2018). Pragmatic Aspects of Scalar Modifiers: The Semantics - Pragmatics Interface. Oxford: Oxford University Press. https://doi.org/10.1093/oso/9780198714224.001.0001

Strawson, P. F. (1950). On Referring. Mind (New Series), 59(235), $320-344$. https://doi.org/10.1093/mind/LIX.235.320

The British National Corpus, version 3 (BNC XML Edition). (2007). Bodleain Libraries, University of Oxford, Retrieved April 25th, 2018. http://www.natcorp.ox.ac.uk/

Woolf, V. (1980). Mrs Dalloway. Mário Quintana (translator). Rio de Janeiro: Nova Fronteira.

Woolf, V. (2000). Mrs Dalloway. London: Penguin. 